Hitum inlos Panwja'TRNDRDE,

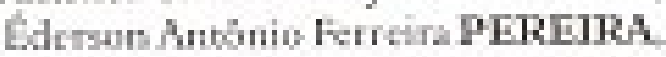

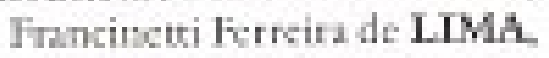

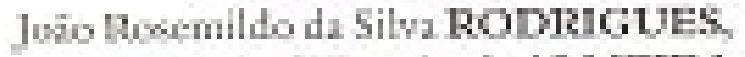

Kris Surli fircir de ALMEIDA

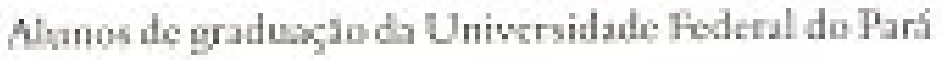

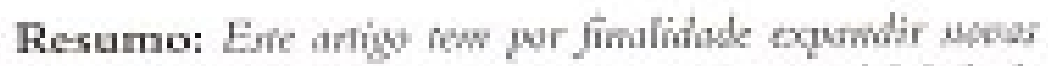

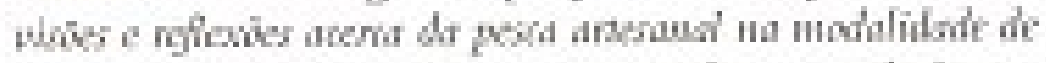

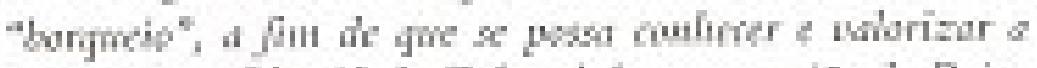

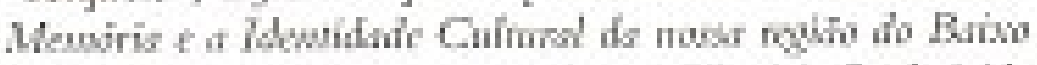

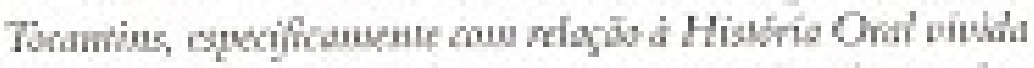

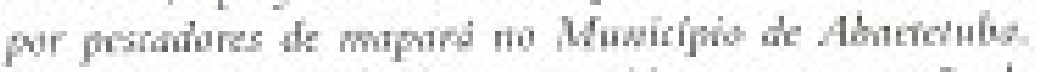

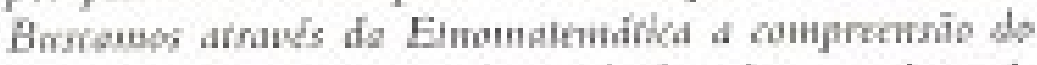

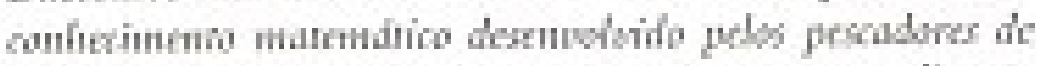

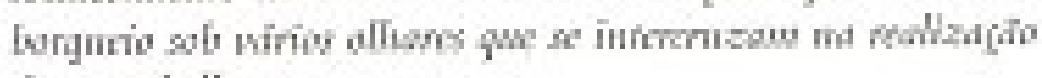
dich tribulles.

\title{
Consideraposes Inicisis
}

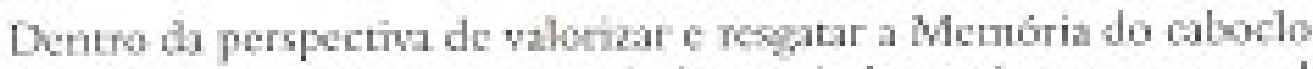

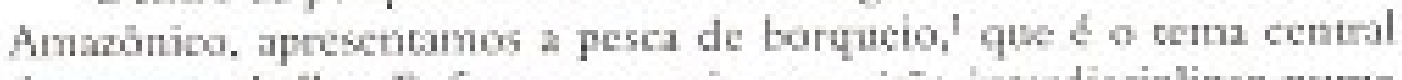

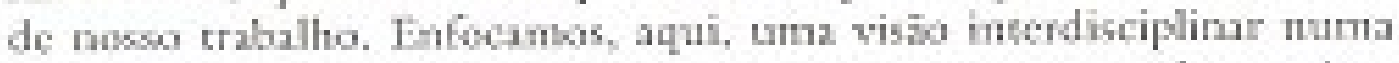

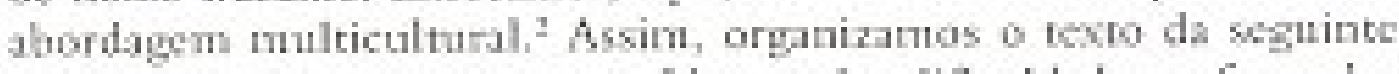

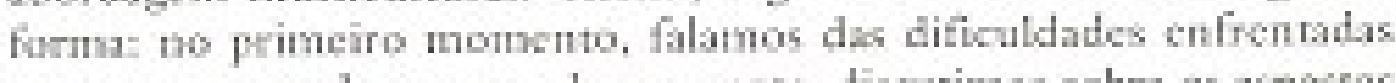

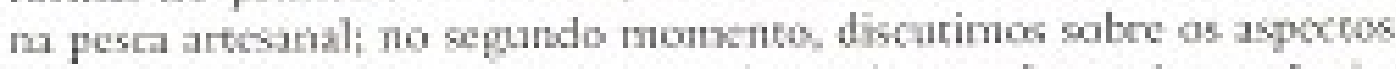

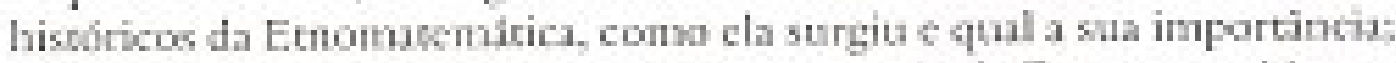

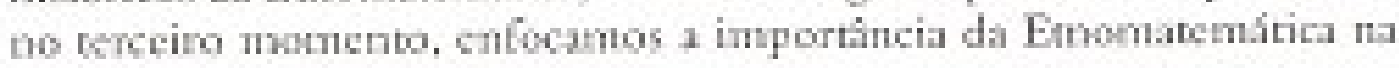

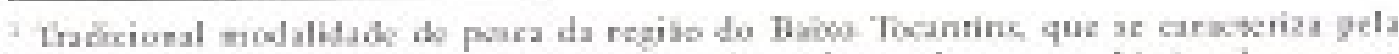

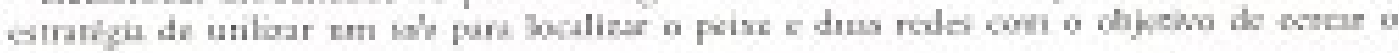
persing

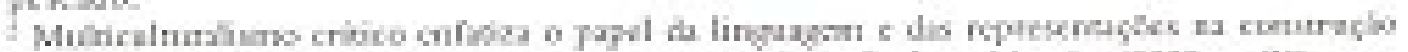

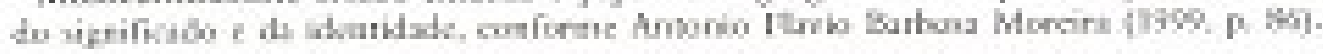

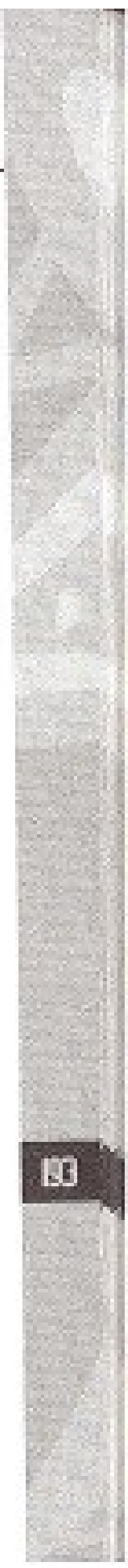


Pesca de bonquab: no quarte momento, apresentamos algumas

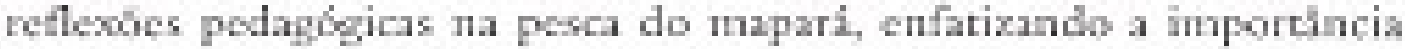

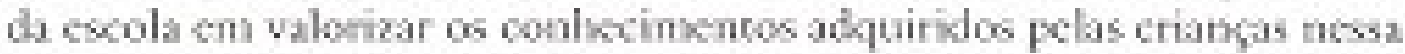

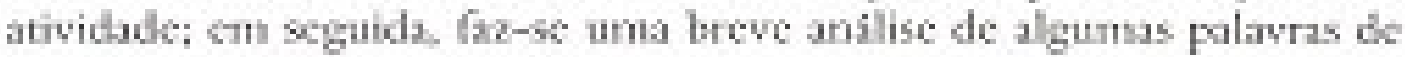

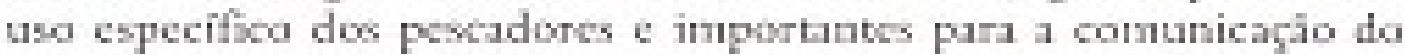

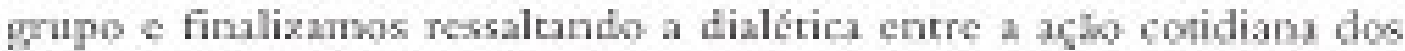
pescaderes.

\section{$1=$ Aspectos Atuais}

A5 questes referenres a posh arcend t sous problemas

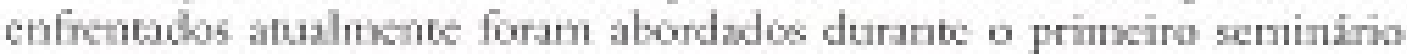

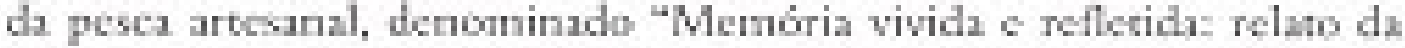

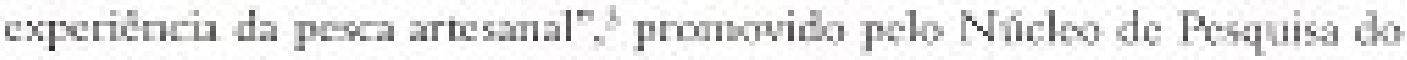

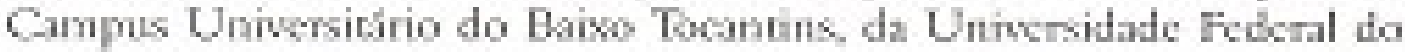

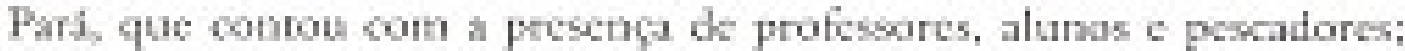

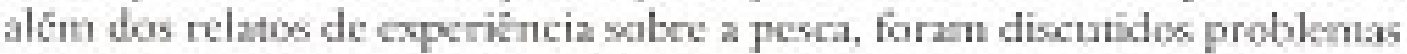

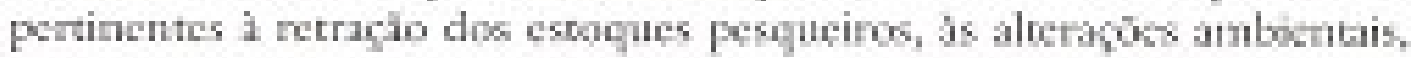

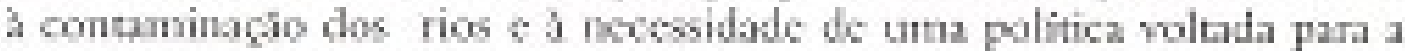

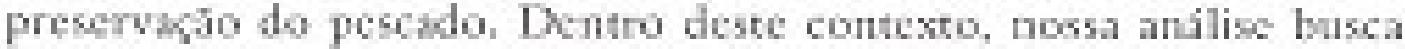

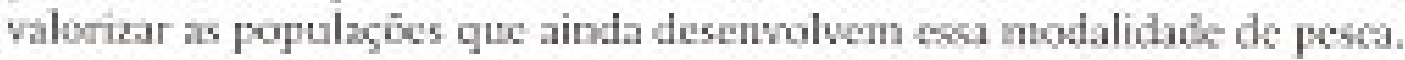

\section{2 - Aspectos Historicos da Eunomatemitica}

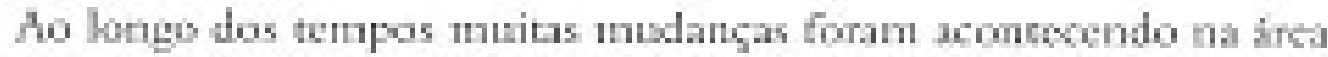

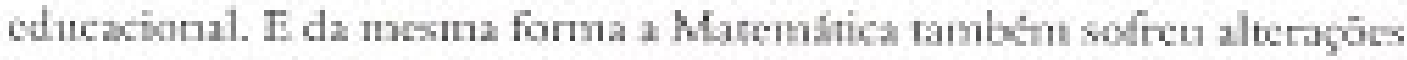
na mancira de ser aplioud his sala de aula. de modo que as alumos

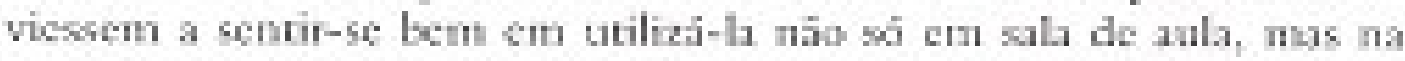
shä rida ontuliama.

Podemos werificar que:

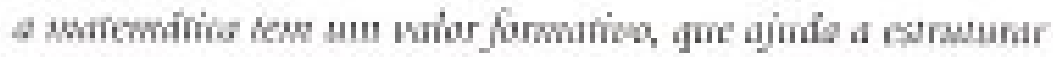

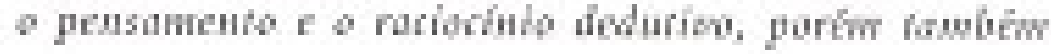

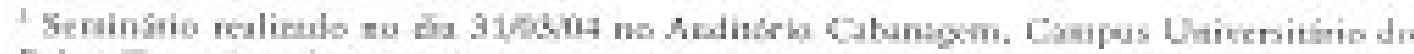

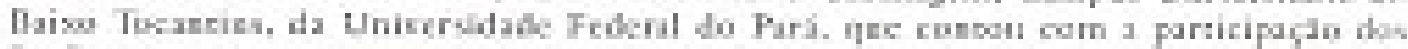

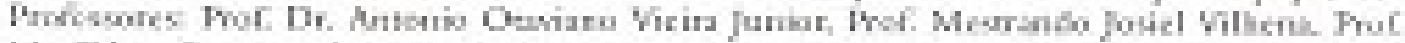

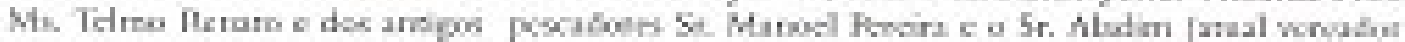

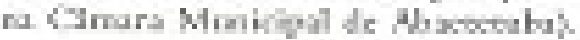




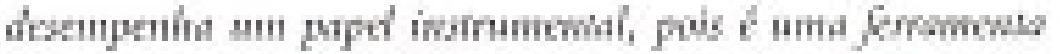

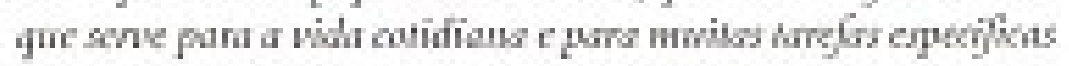

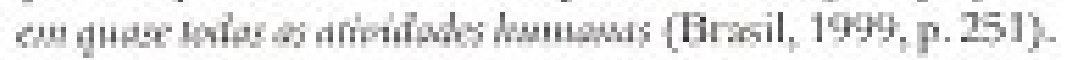

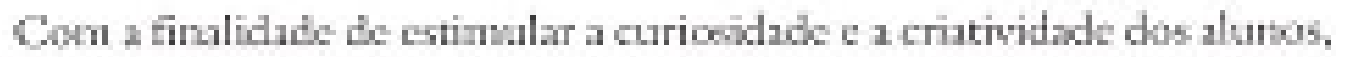

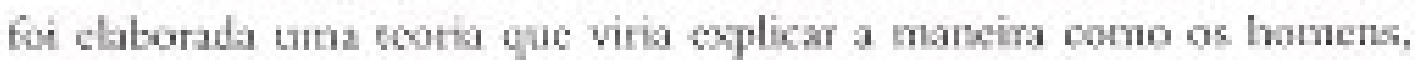

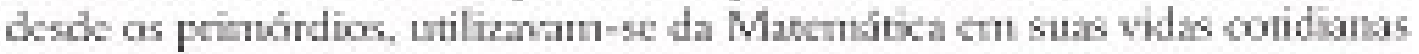

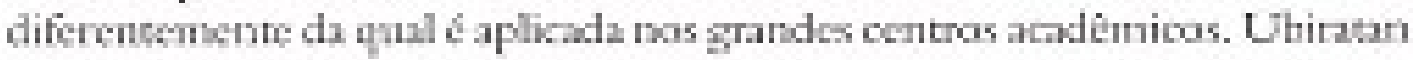

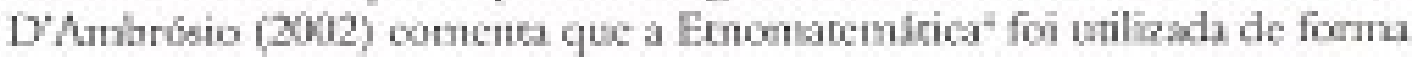

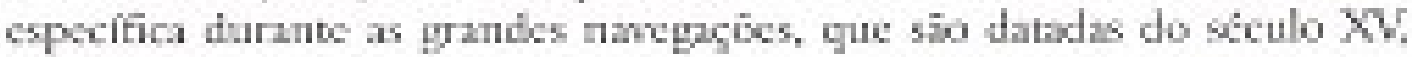
lombrato que nio t ness perlodo que se inicia a vilizapio da

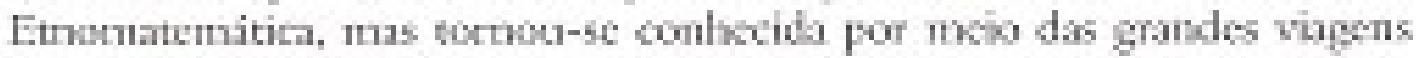
que proporionaram an munda todo o conhocincoto dos povos

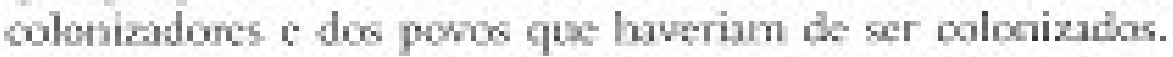

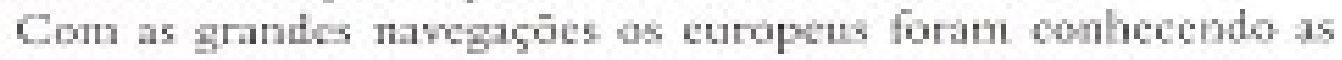
diforentes formas que san urilizatis pelos ponas natros, nas suas

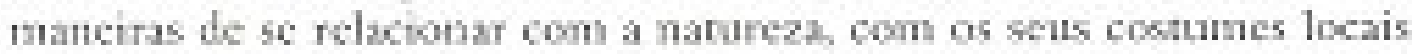

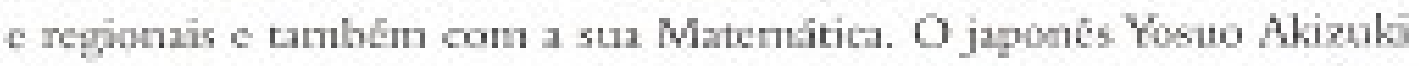

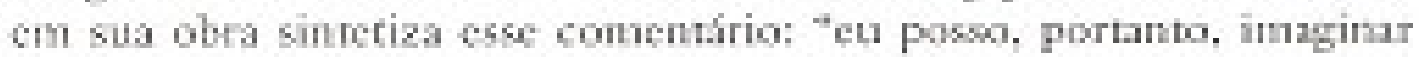

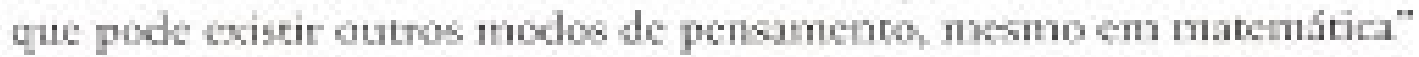

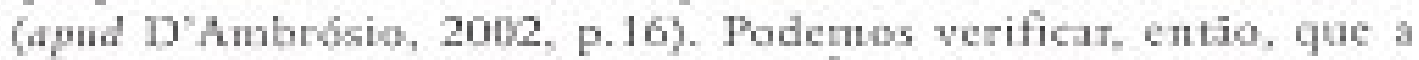
Matubio fot o unieds de fomu difenente da quil a escole repasa

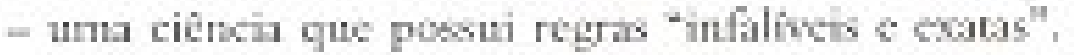

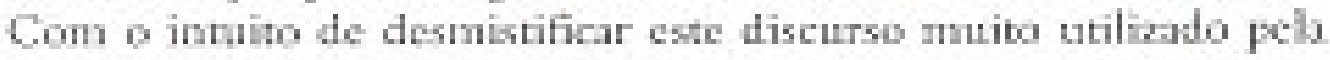

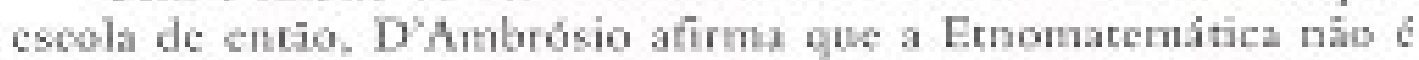

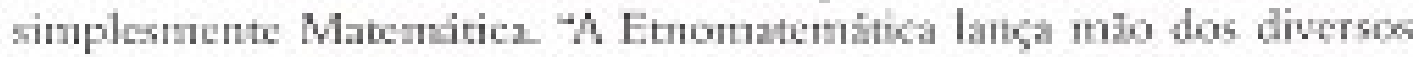

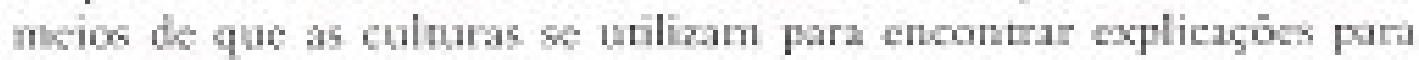

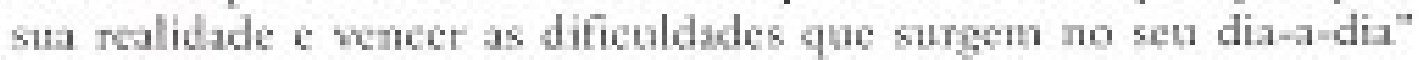
(Wowa Escola, 1493, p. 10-11).

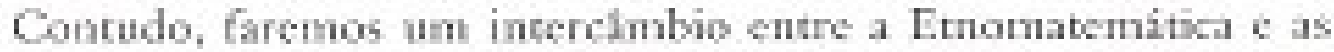
connaidades ribeirinhas da Regiso do Bako Thanrins quando clas

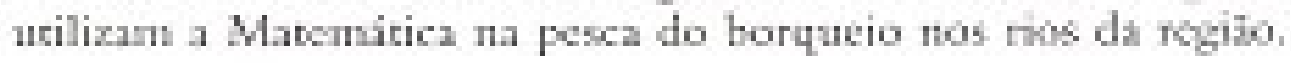

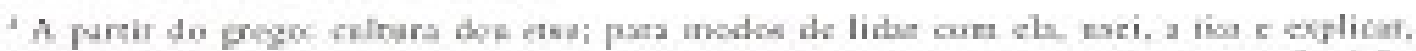

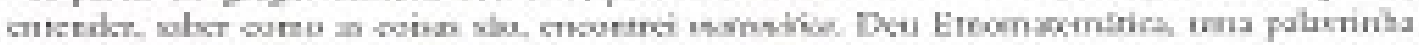

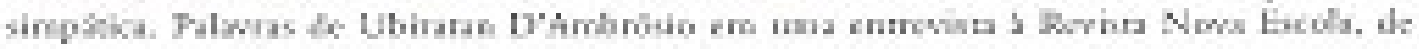
ypare d: 19HS
} 


\section{2,1 - A Etmonatemática e a Matembitica no Cotidtano da Pesen de Borqueio}

0 objetivo fundamental da Enombendricts 4 respeint as

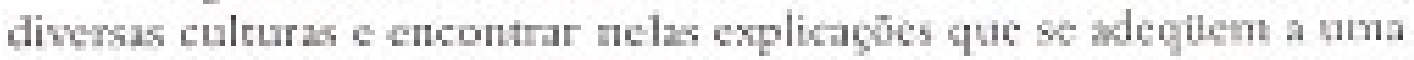
Thalidude socill, diminuindo is dificuldades do cotidiano, utihando retarsos que fuclinch o crabalho para o despertar da curiosidade ed

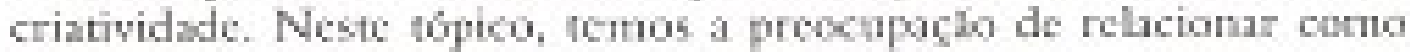

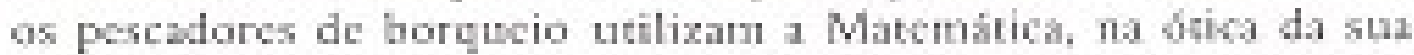
propria linguzgen, $\mathrm{a}$ informal, con a linguagen formal. a omplo da mitmerici, sibtemas de medidas e proporcho, que sio mostas

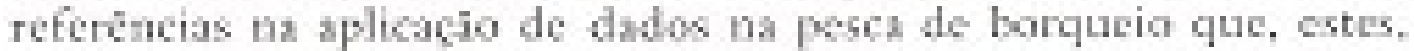
menserados o transformados na posed cono phantidades de

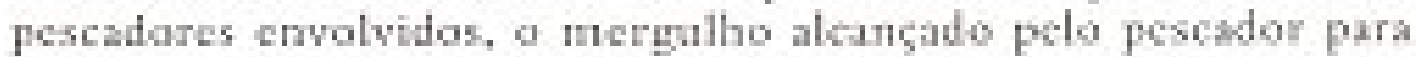
Fechar a rede, a modida de cada "busqueta" coutos instrumentos do que iremos tom mals adiante.

0 s-pestodor roceda quando iniciou bem jowem ma pesca do mapari e conta como aptendeu o oficio de morgullador 20 h 14 anos?

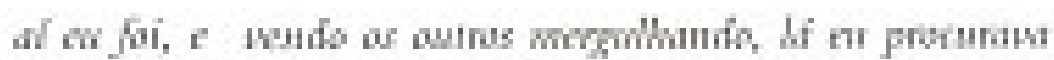

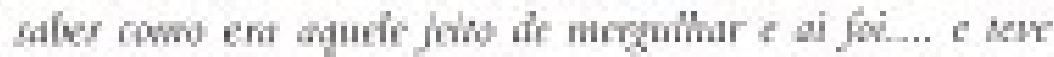

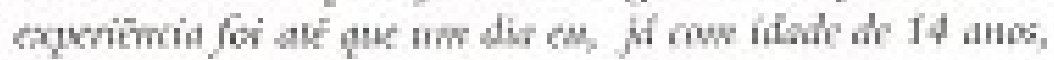

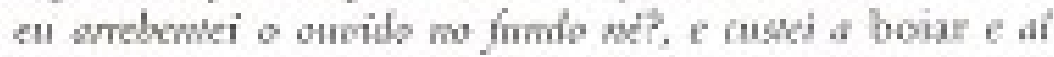

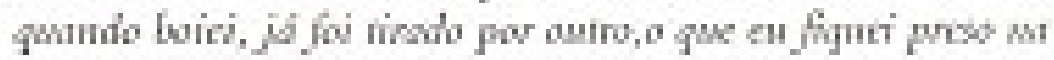

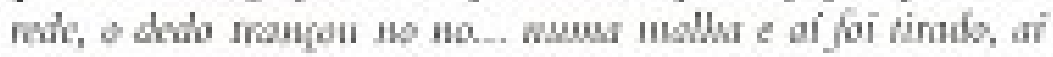

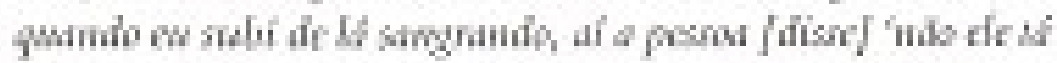

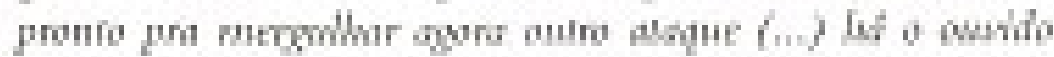

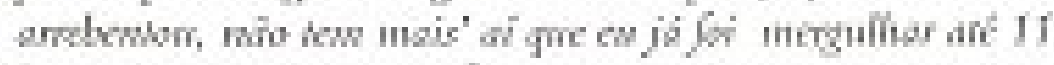
[rogis $[16,5 \mathrm{H}][\mathrm{M} . \mathrm{SP}]^{7}$

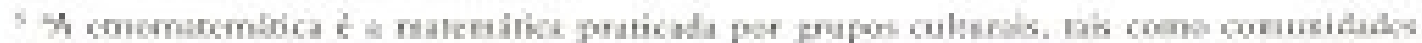

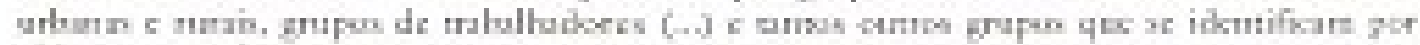

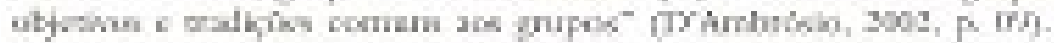

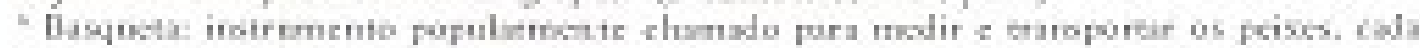

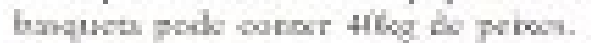

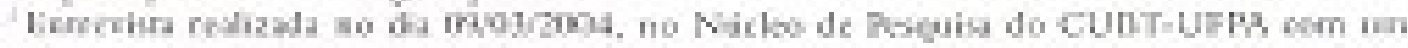

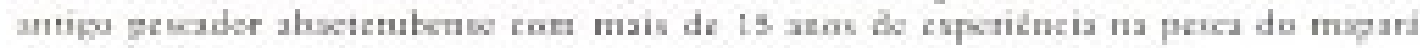

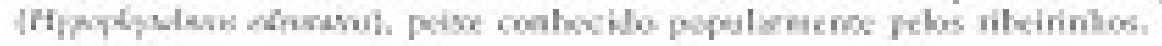




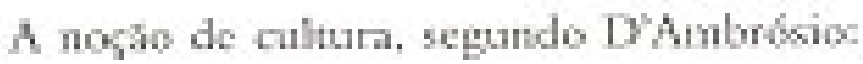

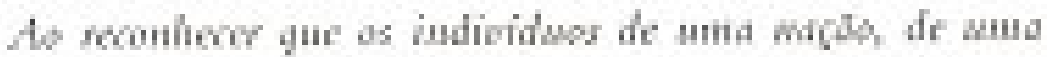

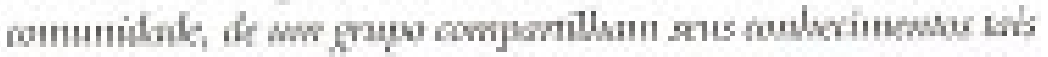

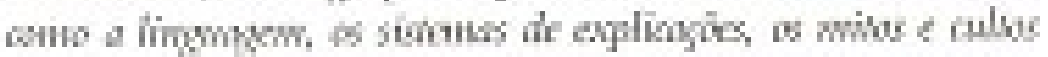

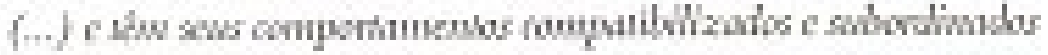

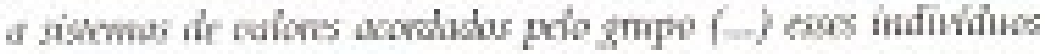

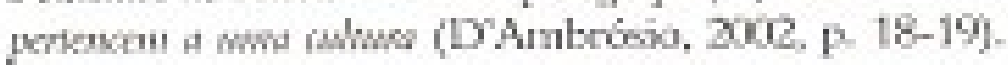

A pest de boigueio zontece geralmente no whe de julho, por

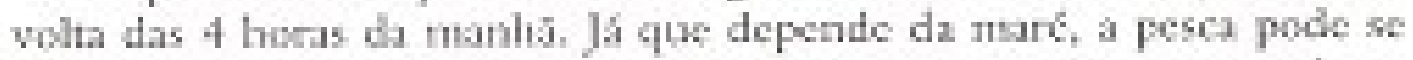

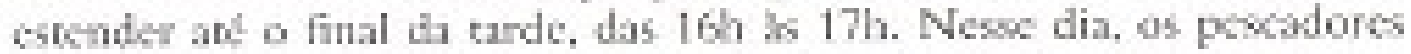

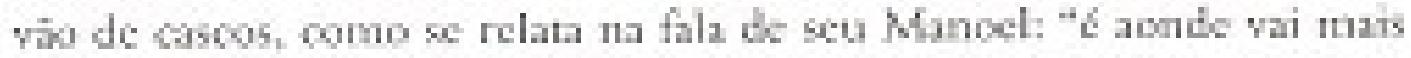

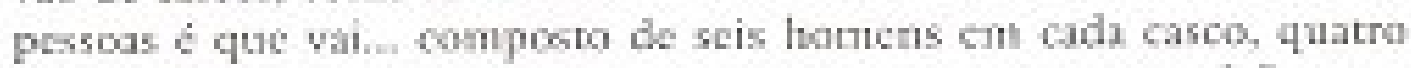

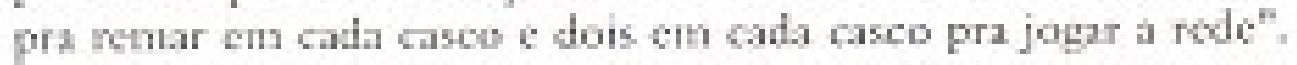

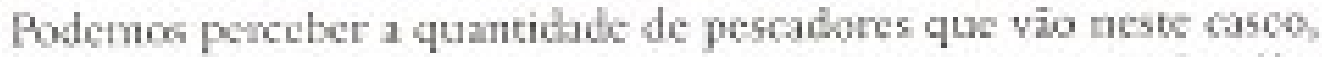

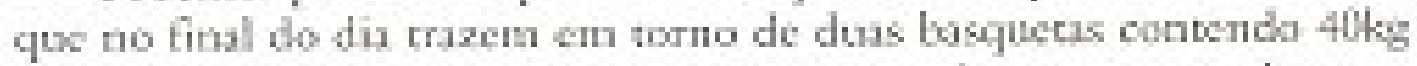

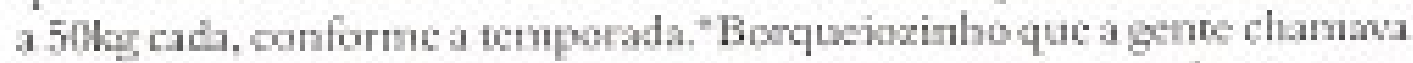

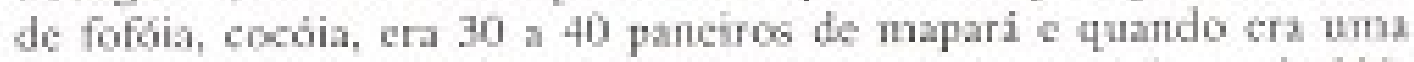

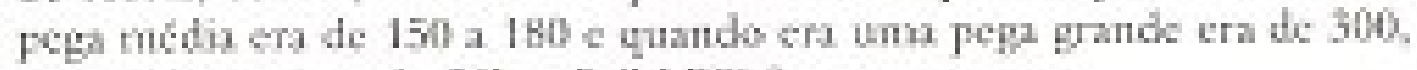
400, 500 pantros do 50he". "R.PS."

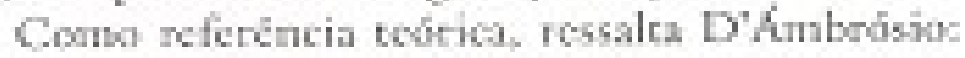

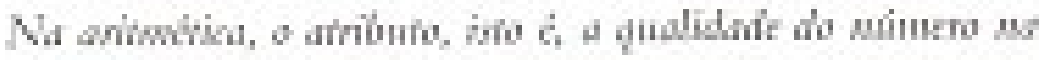

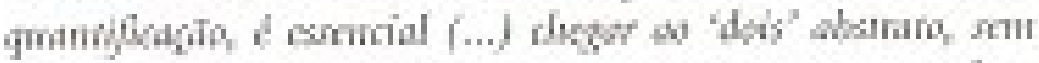

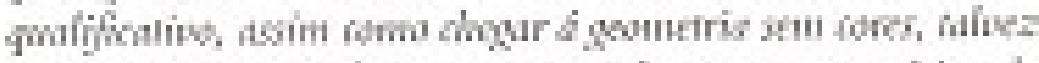

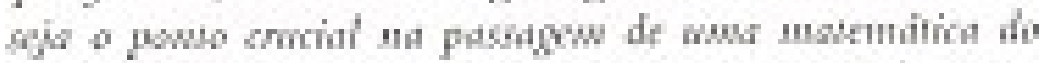

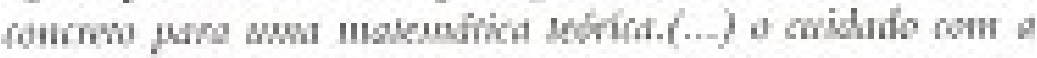

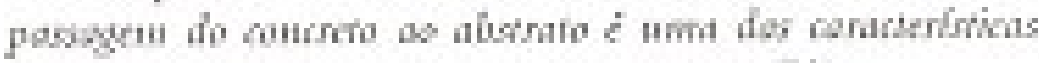

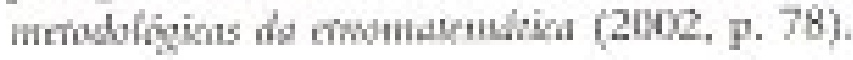

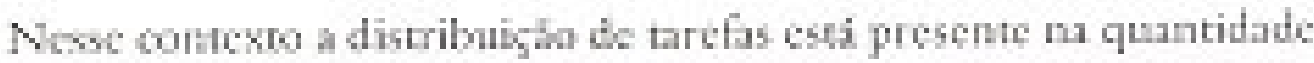

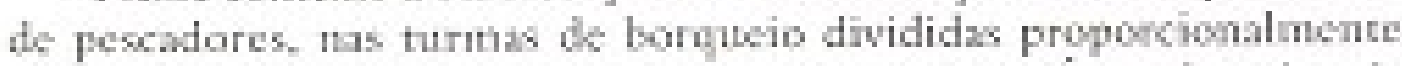

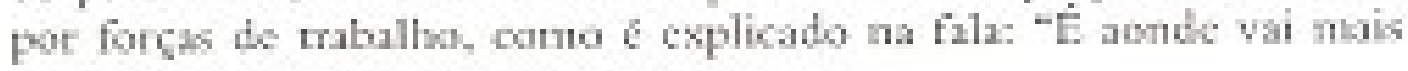

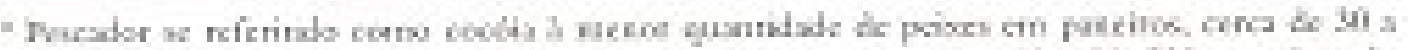

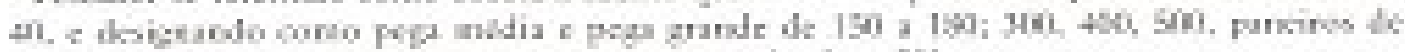

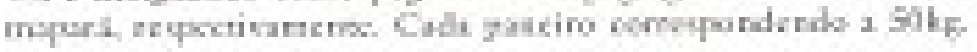




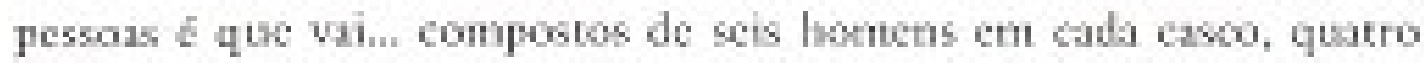

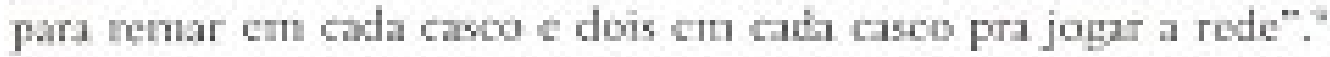

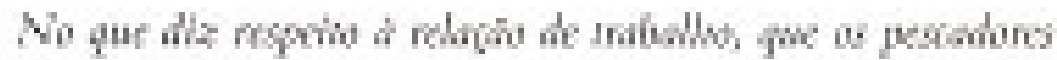

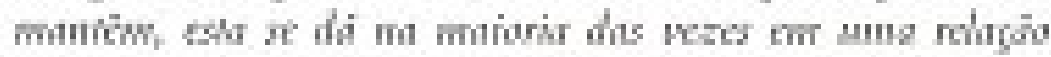

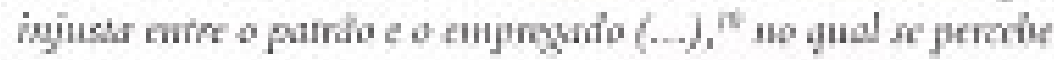

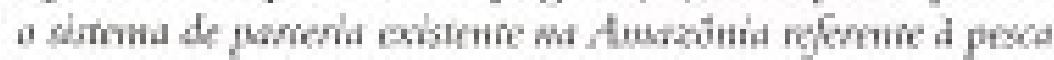

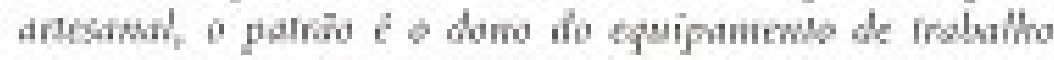

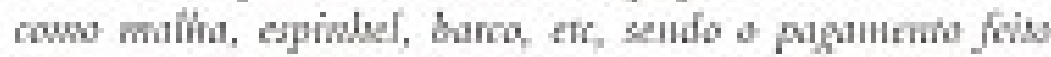

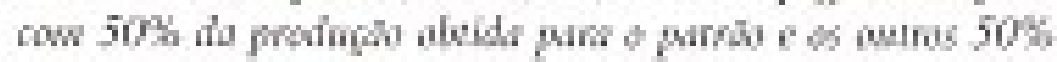

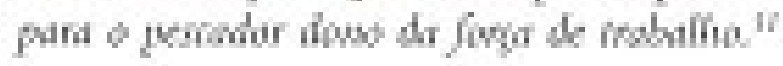

Durante a pesca sio utilizada rodes feicas om linha anericuna

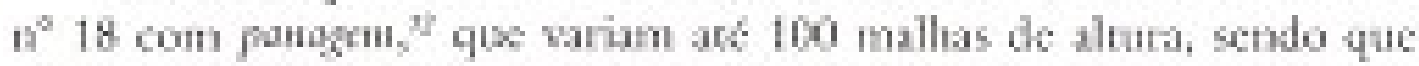

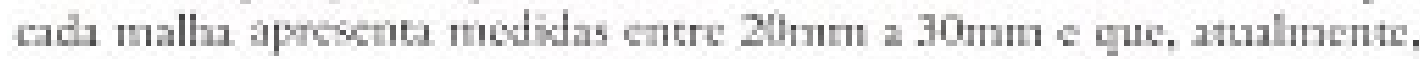
co percadores se utilizan desses redes contribuindo nubém para a

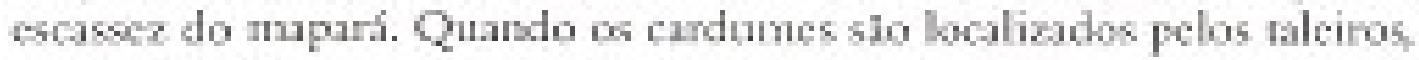
ora pela tala ora por sondz fusi-se a partir de tries metros de protundidadej, \& que e langda a rede. Depos de algun ecmpo, cutra en cena outro personagen, w mergulhador do borqueior o scu

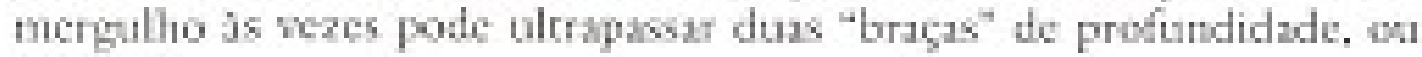
seja, 3m.

Os taleiros exeren uma dis funches findanchesis na pesed de bormesio, como ohservames na fala:

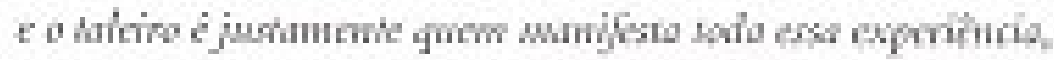

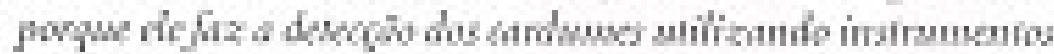

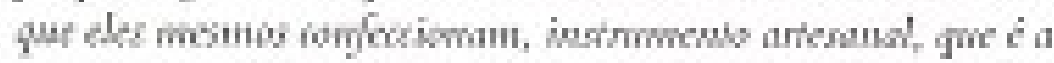

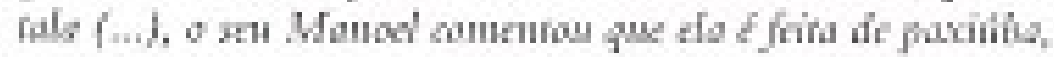

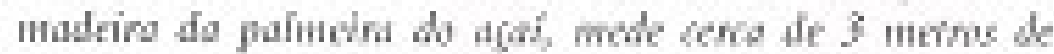

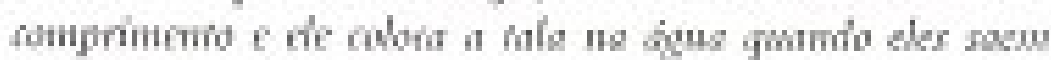

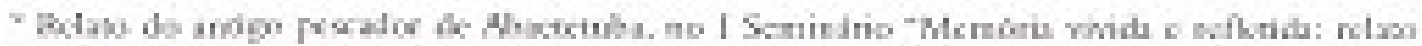

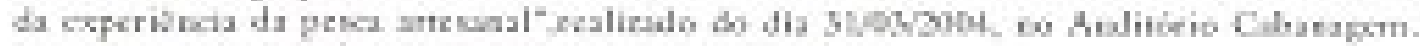

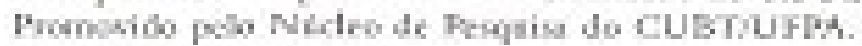

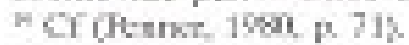

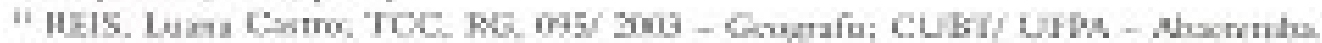

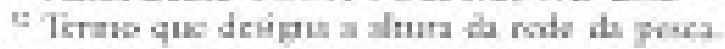




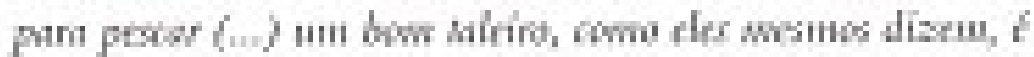

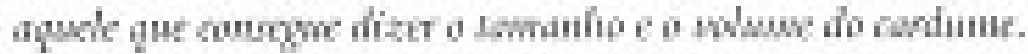

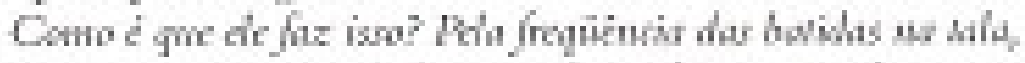

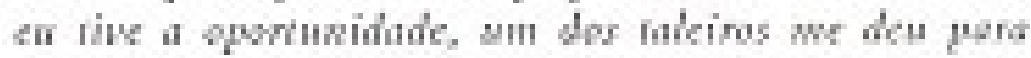

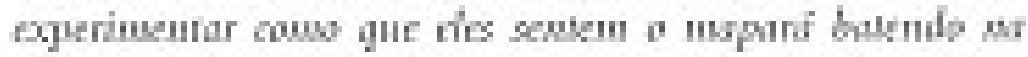

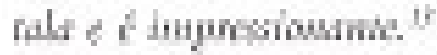

\section{3- Reflexues Podagogieas Sobre a Pesca do Maparä}

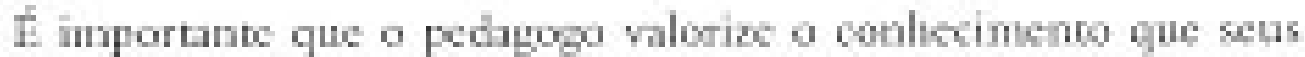

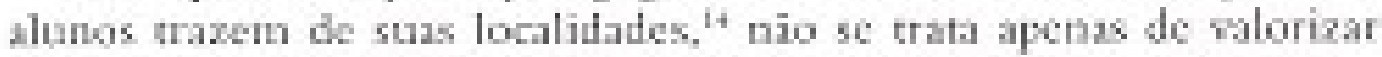

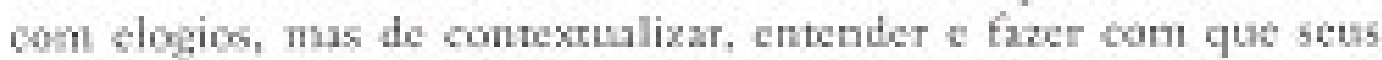
alunos posam aprender a licha dos livros sem perder de vista suas

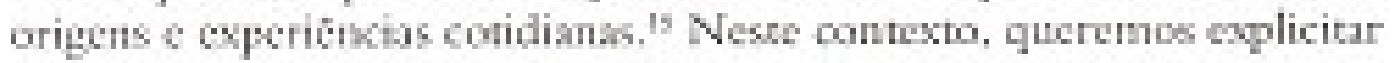

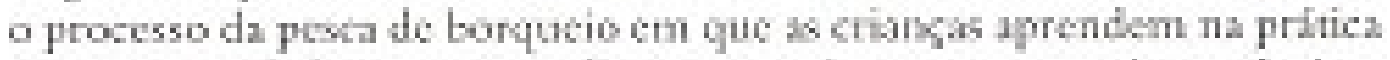

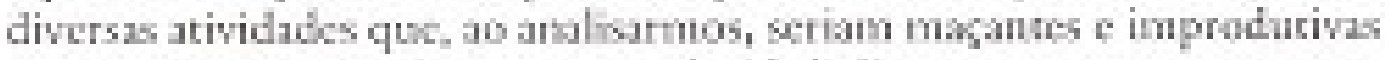
en sale de anle devido a sua complexidatio

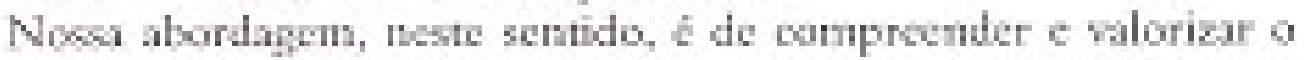

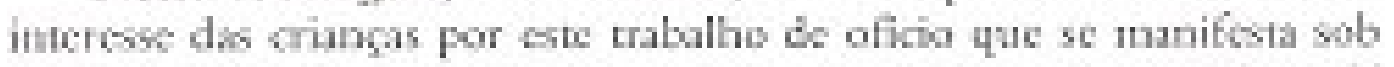

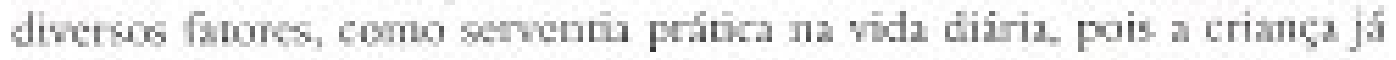
entende que aquila arivide pesqueira 6 importante para sua sobrevincinia. Guro fator is a colaploxidude do processo da pesca, que cxige aburasio e cuidudo no mantisco dos equipumentas, o que,

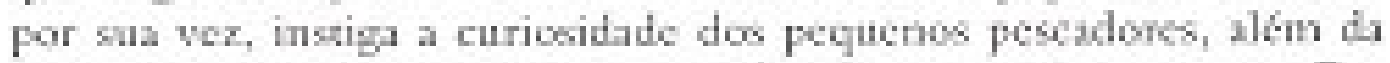
socinlizaclo da atividade que of realizada por viries pessas Em contraporridi a cach realidade, a escola deveria ser a locul ondo as experibnclas das criangs fospen valorizadas com obsenincia das

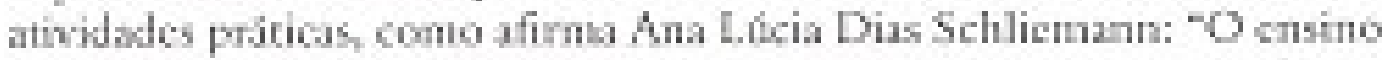

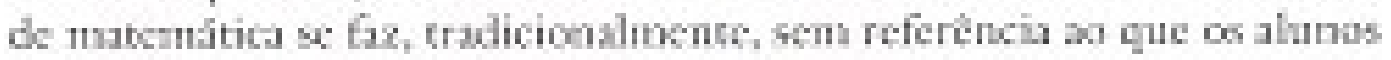
ja saber" (2001, p. 21$).$

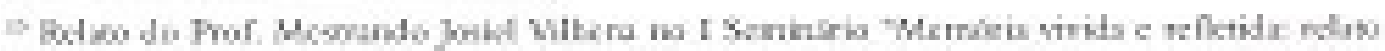

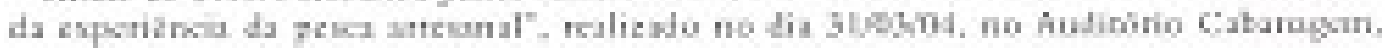

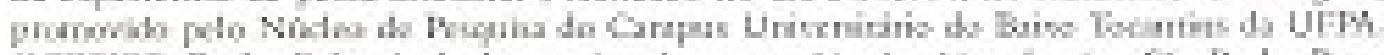

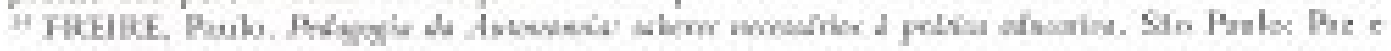

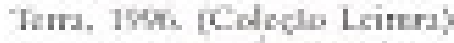

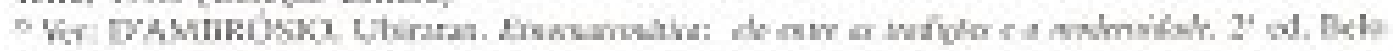

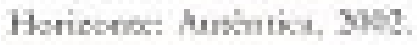

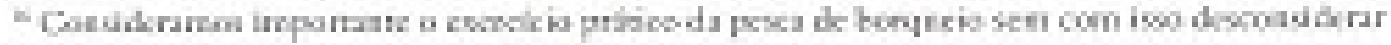

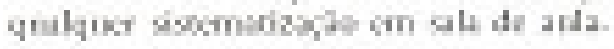

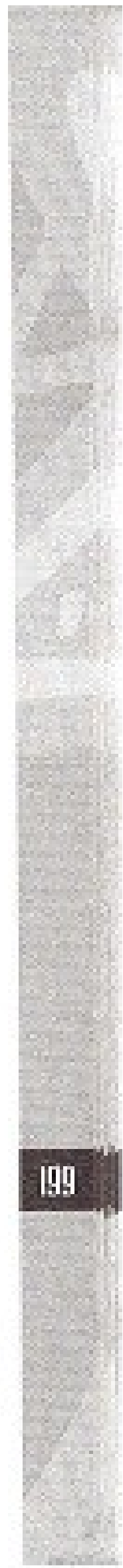




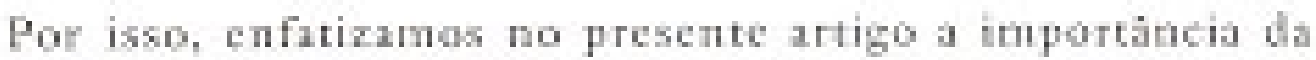

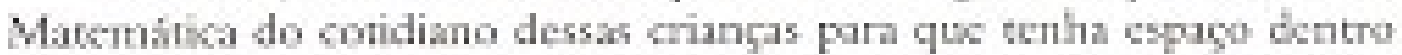

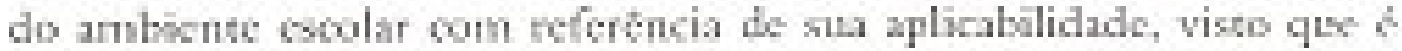

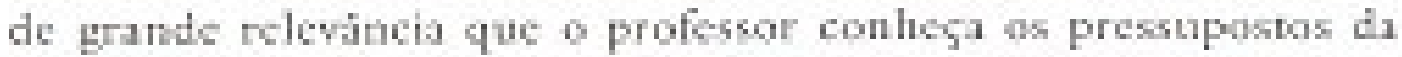

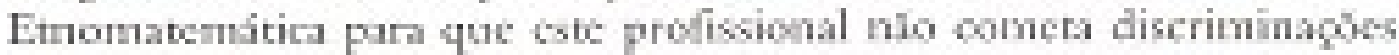

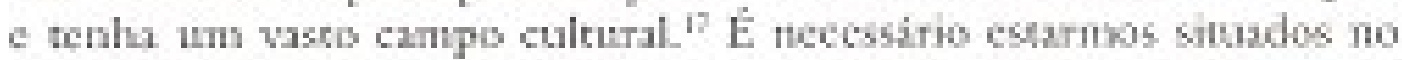

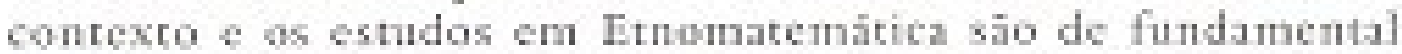

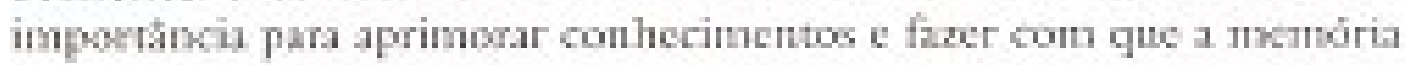

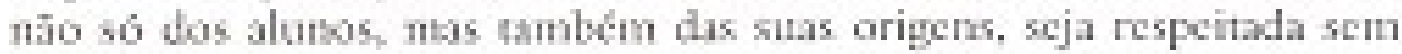

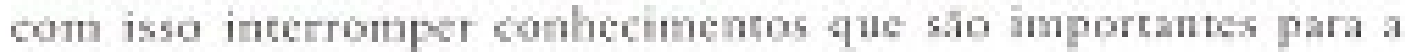
formaço do individuo.

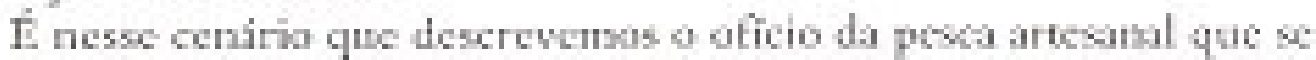

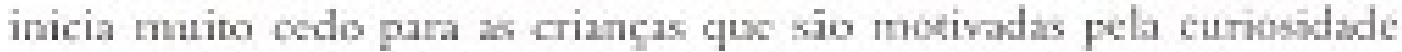
de apender a profichon do pai ou de sm parente mais velho, na qual

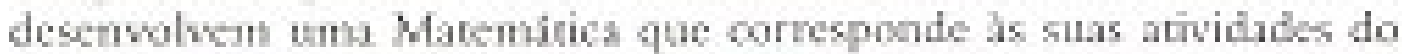

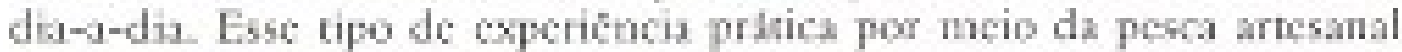

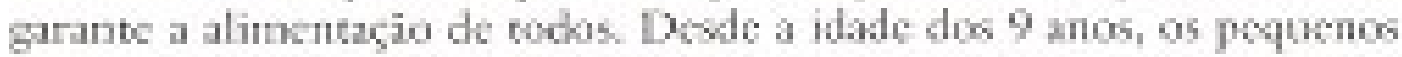

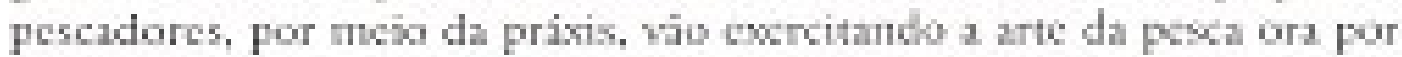

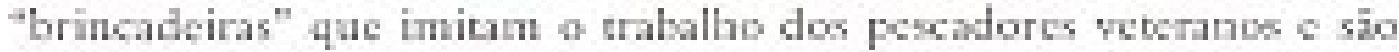
contudas por cles como ama "drversas", ora cong uma atividude

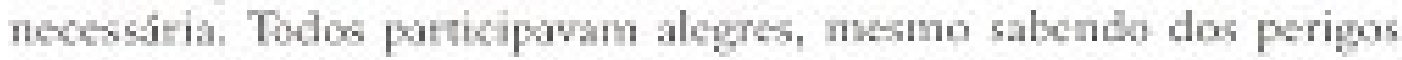

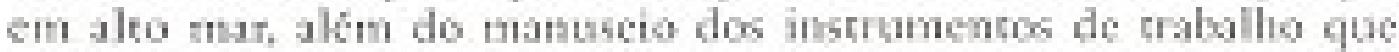

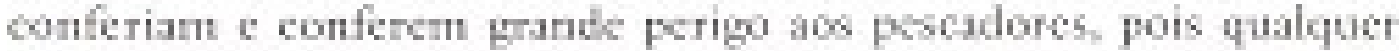

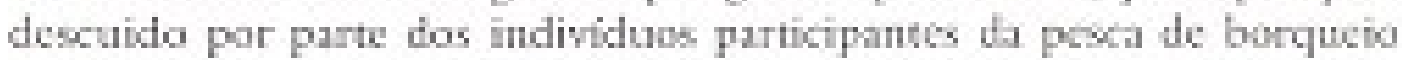

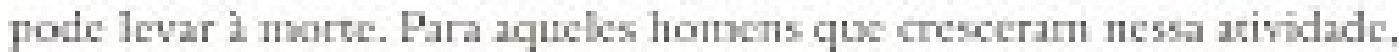

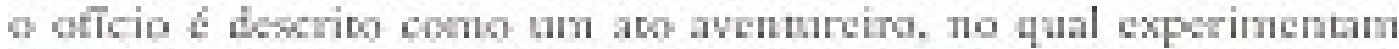

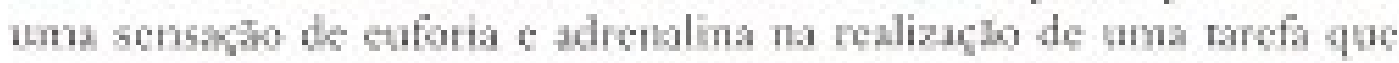

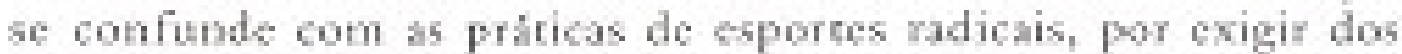

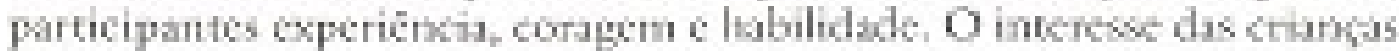
Fur esce ripo de arividade demonstra que o oficio da pesca tem relativamente una importincis pritin nas suas vivincias s que foge ha

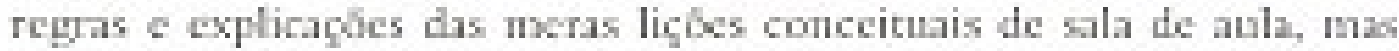

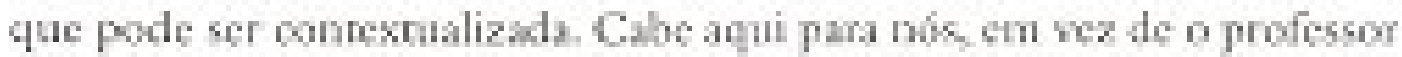

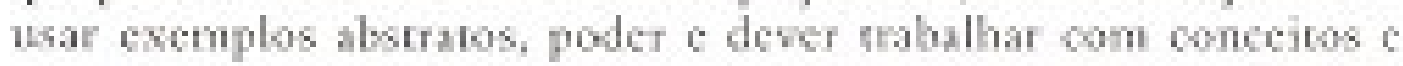

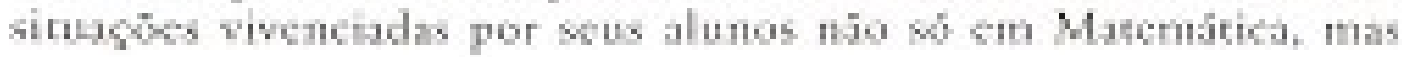

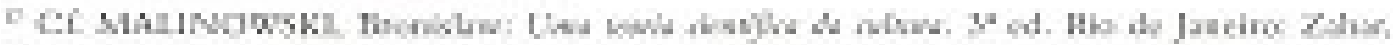
105. 
tamben em outras diciplina, transformando o ato "ensing of aprendizen" muits mais agkhwel.

\section{4 - Aspectos Linguisticos da Pesen do Mapard}

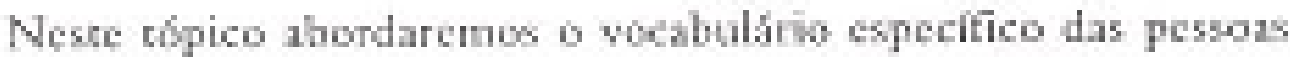
cowotvids na pesca do magari e os sus nepseriog signifindos para o Brupo.

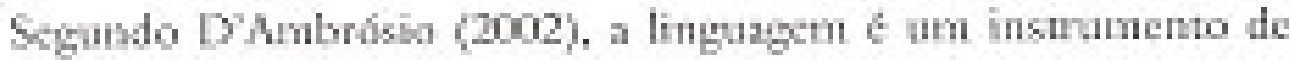

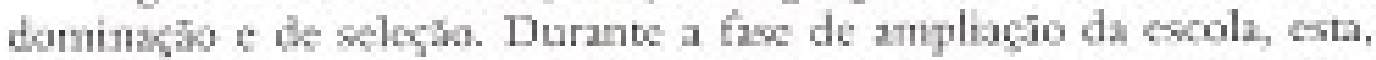

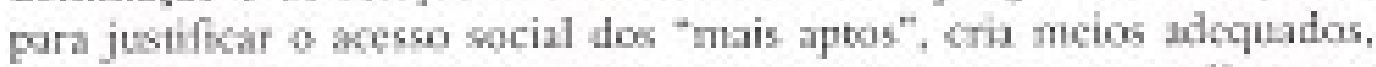

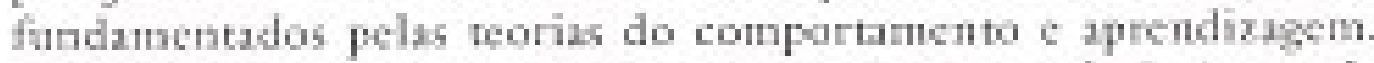
Primairo tomou-5e omo pudno a latim, depois o sulsotutran pela norma padrio da ligghgen, e cumbdin a Matemitica se tornot ese instrumento seletivo. E ihpordune lembrar que essa linguagen utilizada pelos postadores de borgucio of fundamental para a combnicaça interm, visto que da ju the parte da cultura deles of

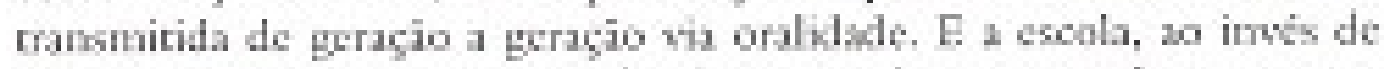
lapidars aprimorar, esses coghecintatos, incotporando o novo e

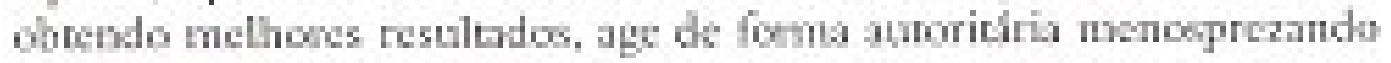

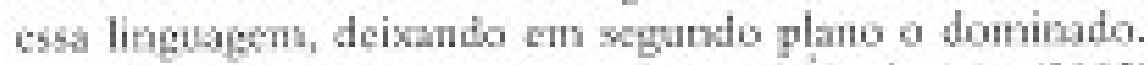

Nest conrego, sinda conforme DMmbrosso $(2002)$, a wertente

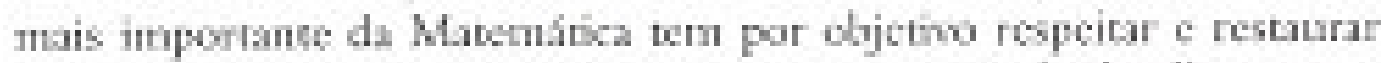

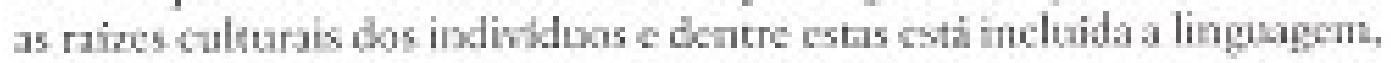

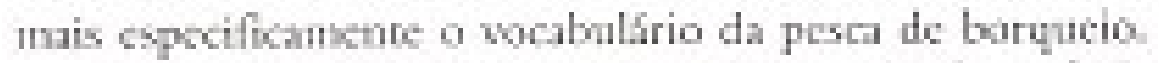

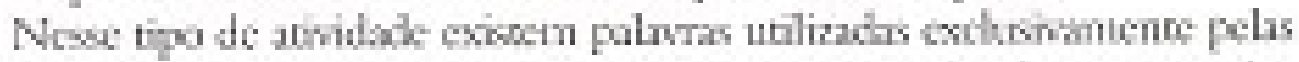

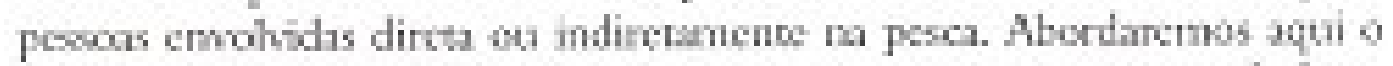

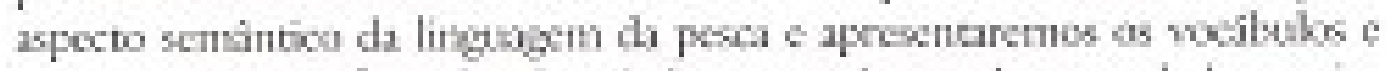

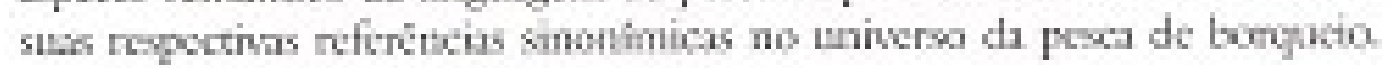

Apresentarcmos alguns woblbulas

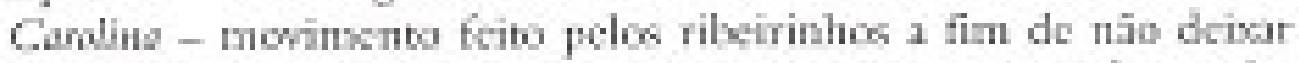

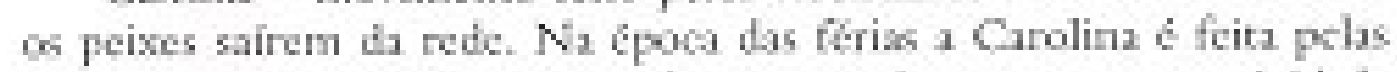

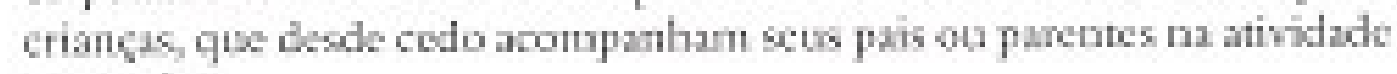
pesqueits.

Thin - pesiog muito cxperients que ugiliza umb tala feira de

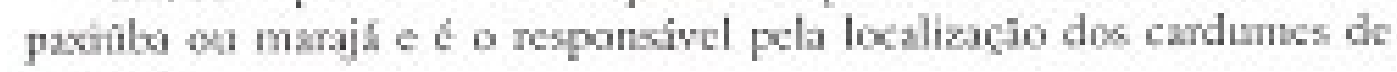
maparis,

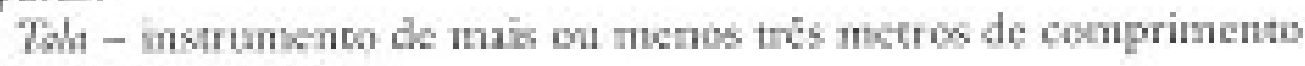
utilizado pelo talcino.

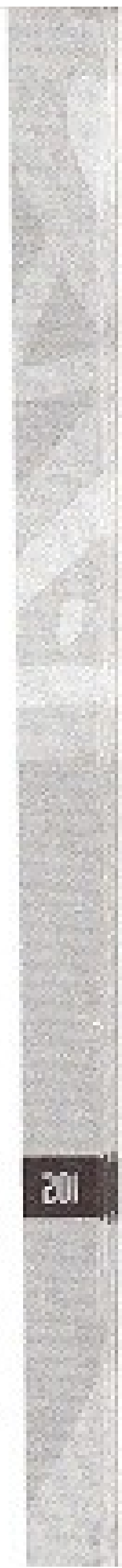




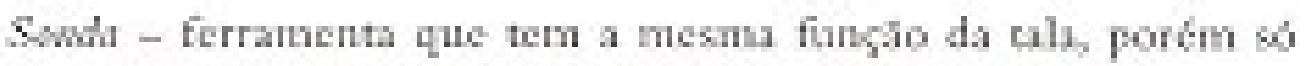

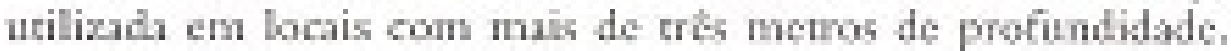

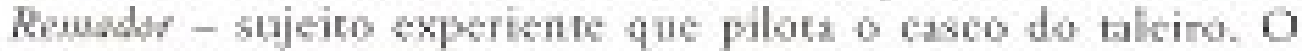

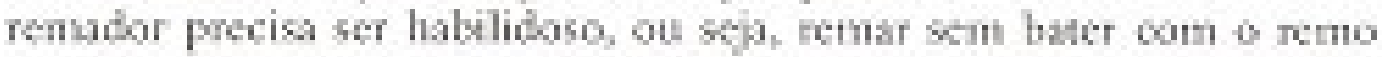

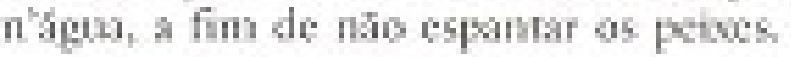

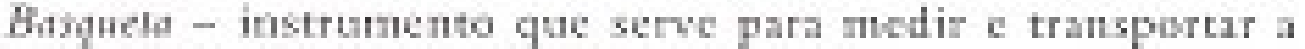

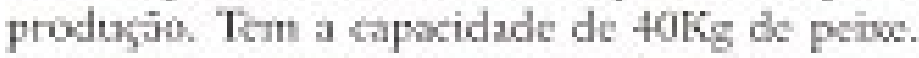

Parire - instumento tradicional tanbon utilizato para medir e trangortar os peikes.

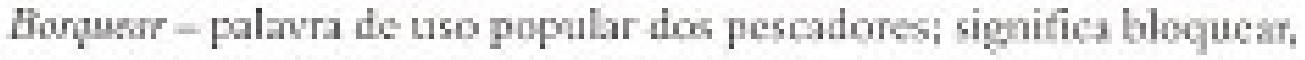

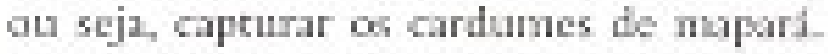

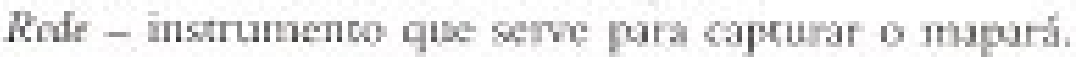

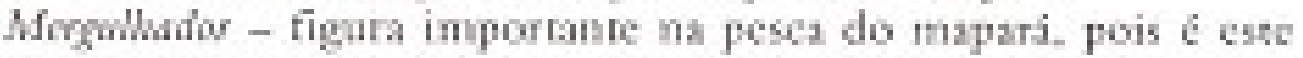

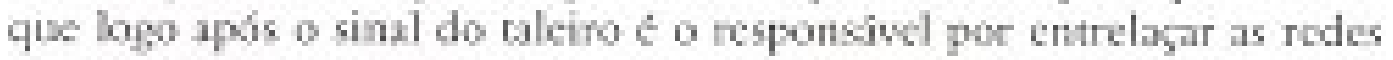
ath bawa digiz.

Puswons if mit - so trabalhators que tim 1 funcio de reoulher as rodes

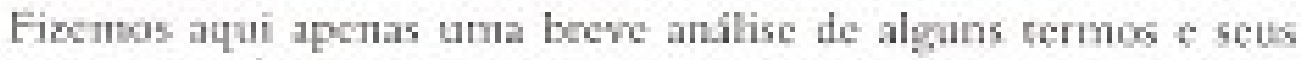

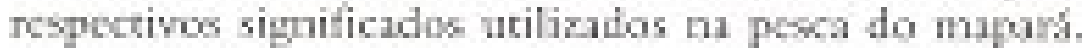

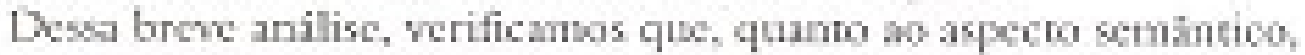

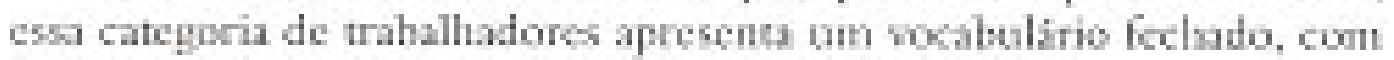

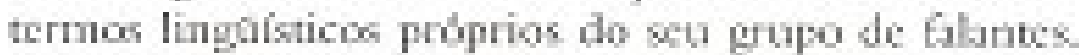

Descobrimos aqu as povadores de maperí apresentan แma

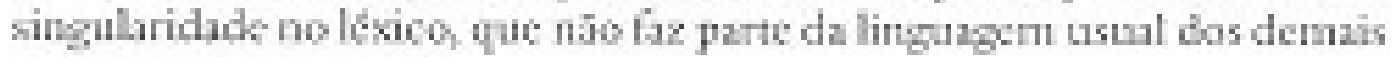
moradome dis regito

\section{Gomsideragore Finais}

Contuimos nosso trabulho, mosmande a nocscidnd de wha abordagen incerdisciplinar volodi pos a rolldate da ontunidades

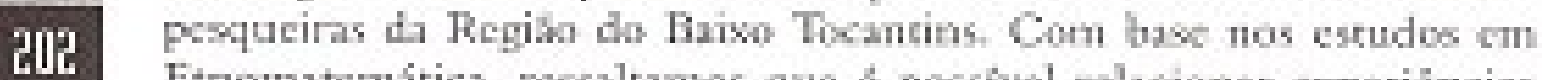

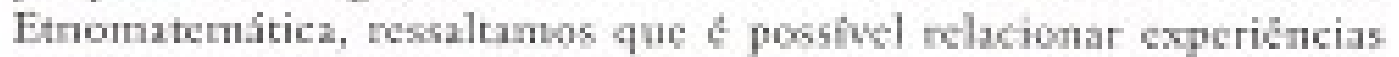

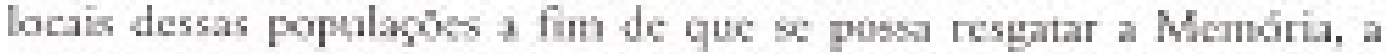

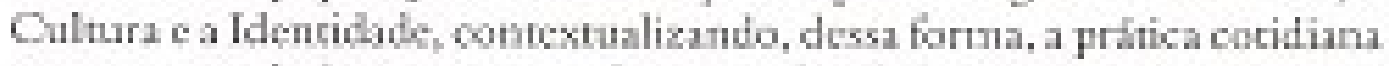

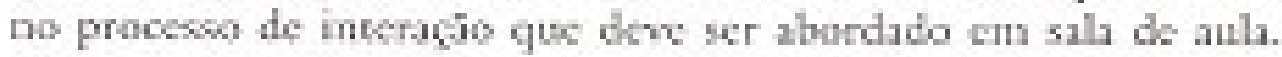

Tanthut pudenos prober dentra dess visio incerdikiplinar

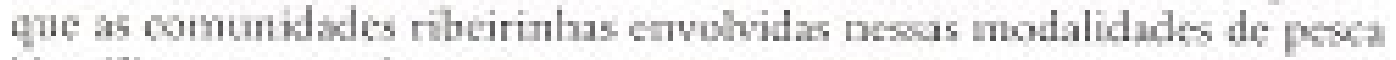

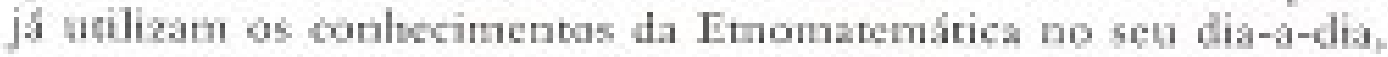

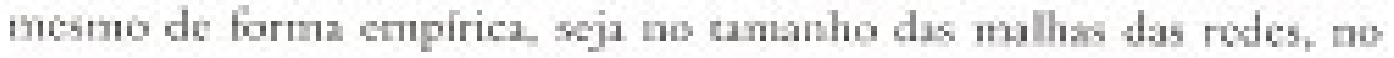




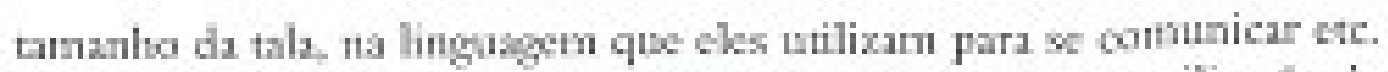

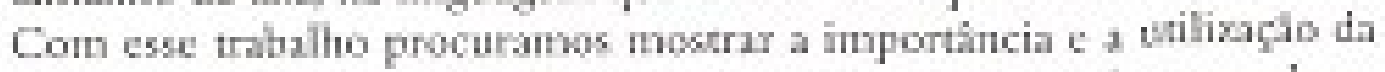

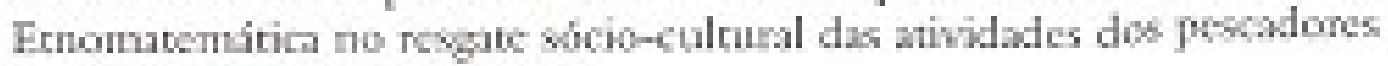
da Megio do Baw Toungits.

\section{BITLIOGRATIA}

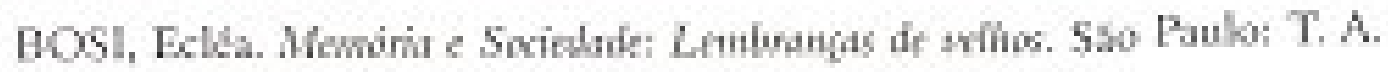
Duthe, 1979.

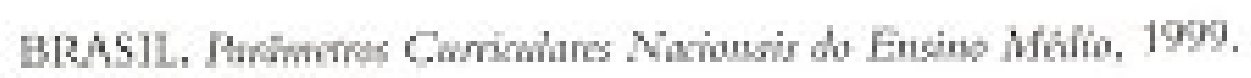

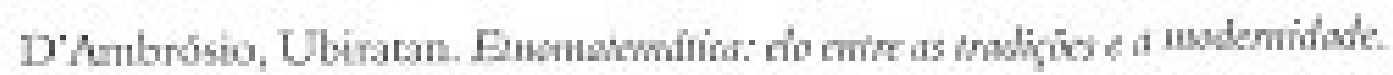
z" ed. Bth Horkoin: Autrica, 1002.

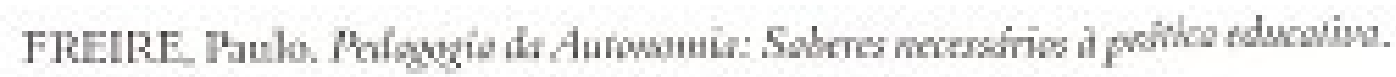

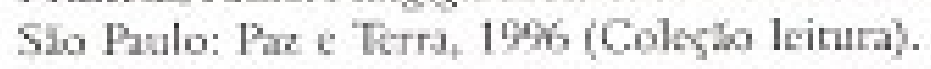

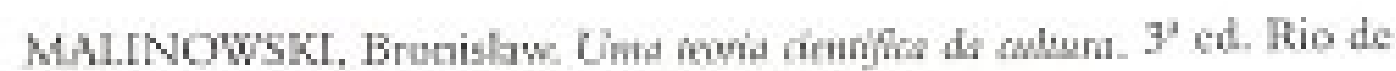
Jan:m: Zahr, 1975.

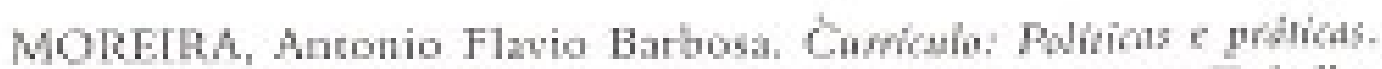

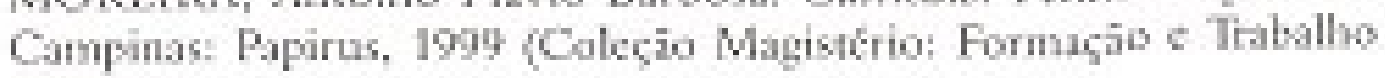
Hedigogin).

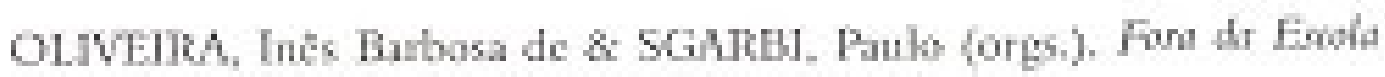

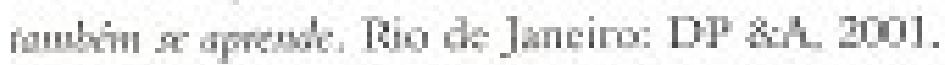

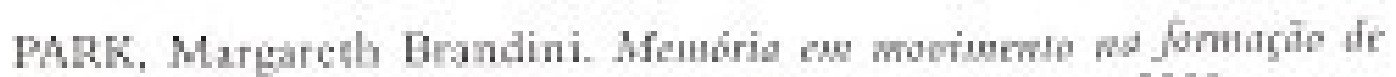

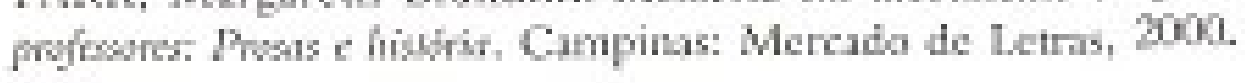

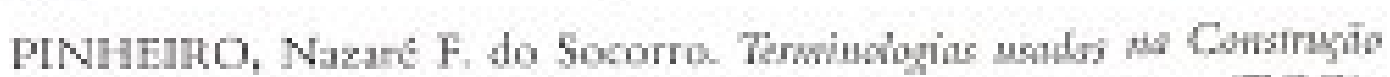

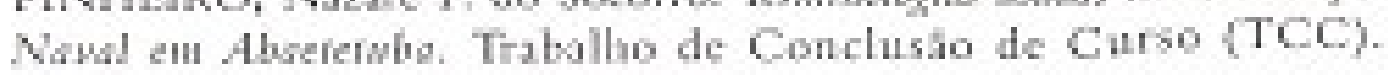
Abocuhi: CFPA, 1973.

WOW ESCOLA, yow do 199.

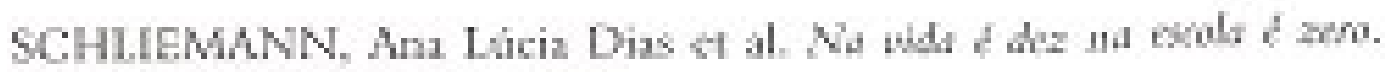
12 t. Sin Fualo: Cortes, 2001.

Artigo recebido no dia 27 de abril de 2004 e aprovado no dia 23 de agosto de 2004. 